\title{
Free Fares Policies: Impact on Public Transport Mode Share and Other Transport Policy Goals
}

\author{
Nils Fearnley \\ Institute of Transport Economics, Norway \\ naf@toi.no
}

\begin{abstract}
This article investigates the merits of free public transport as a means to achieve a number of transport policy objectives, including mode shift towards public transport. It outlines some political and societal motivations behind proposals for free and low fare schemes, and presents key economic principles for public transport pricing. Examples of free fare schemes mainly from Europe are summarised and their impacts synthesised. Although free public transport at a first glance may seem attractive both from economic, social and environmental perspectives, the message learnt from a number of schemes is that free public transport offers poor goal achievement in all these respects, and at a high cost. The main effect is a huge growth in patronage, up to 13-fold increase is reported, of which the larger brunt is shifted from walk/cycle, or induced. The effects on car traffic levels are marginal and typically they are offset already after a few years' traffic growth. Successful free public transport schemes are those whose goal is mainly to grow patronage. Congestion relief, social and environmental benefits are best achieved with more targeted measures, or in combination with such measures.
\end{abstract}

Keywords: urban public transport; free fares; mode shift

\section{Introduction}

It is a widespread view across the Western world that urban traffic levels and the private car's market share are not sustainable. The economic dimension includes soaring congestion costs and inefficiencies in terms of external costs of transport. The environmental dimension is ubiquitously apparent with greenhouse gas emissions and local pollution problems high on the global agenda. And the social dimension includes welfare losses and reduced mobility. The current conditions and forecasts do not match the goals and visions that are formulated in policy papers from all levels of government from municipalities to supranational bodies, like the EU White paper on transport [1]. The ambition in the Norwegian White paper on climate [2] is, for example, that public transport, walk and cycle shall take all future urban passenger transport growth. And the EU's Action plan of urban mobility [3] sets out priorities for optimising urban mobility through, e.g., "affordable and family-friendly public transport solutions" (p. 10).

The perceived need for political intervention for a better urban transport is widespread. The international Association of Public Transport has responded to this by issuing its strategy to double public transport's market share by 2025 [4].

Public transport clearly has an important role in addressing the needs for fair, efficient and environmentally friendly urban transport $[5,3]$. The available measures necessary to make public transport an attractive alternative to the car are largely in the hands of politicians. With their time horizons confined, at least in part, to their electoral period and their focus on re- 
election it is no surprise that their preference and beliefs favour carrot measures. Nossum and Fearnley [6] document that local and central politicians do not only prefer carrot instruments over stick instruments. The authors also find an inherent and widespread belief that carrot measures are more effective than stick measures. A majority of elected politicians and public officials alike state that car traffic problems are best solved with positive measures like public transport improvements, and not with restrictions and charging of car use. Their findings are in line with Frey [7].

The demand for public transport is determined by a large range of factors [8], of which the 'hard' quality factors service frequency, fare levels, travel time and punctuality are generally regarded as the most important ones. As a rule of thumb, one can expect a 10 percent fare reduction to increase patronage by about four percent in the short run and up to double that in the longer term [9]. There is, however, a growing amount of evidence that citizen and passenger satisfaction with the fare level, or value for money, is particularly poor. Despite not usually being ranked highest among factors affecting the demand for public transport, fare levels are invariably a primary source of grief, frustration and dissatisfaction - probably only matched by frustration over poor punctuality. Results of the European benchmarking club BEST's citizen satisfaction survey illustrate this (Figure 1). Satisfaction with value for money lies in general at bottom levels. With an average score of less than 40 Value for money is only challenged by Reliability and Information - both with average scores of just over 50 .

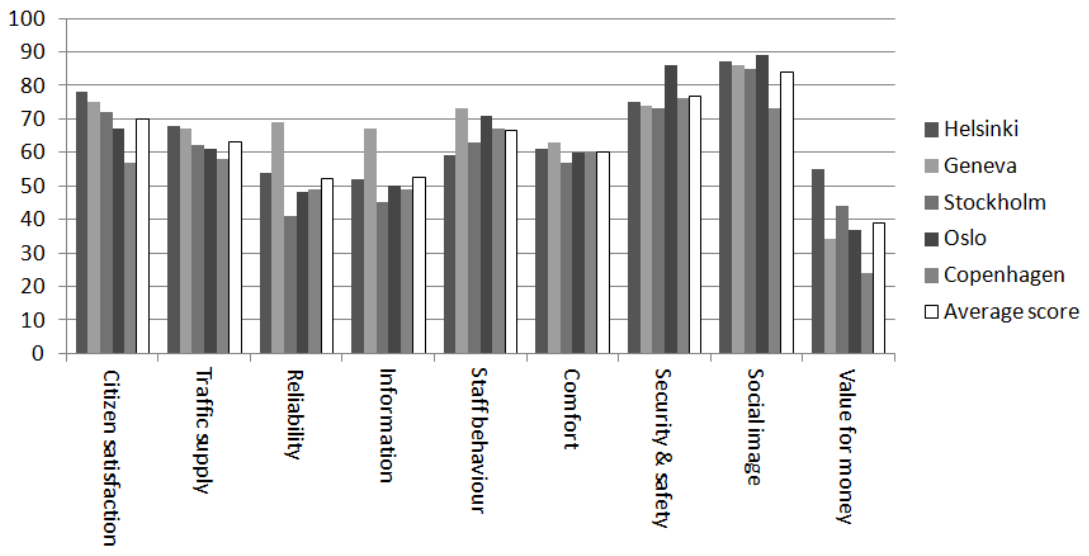

\section{Figure 1. Citizen satisfaction with different aspects of public transport in five European cities. Based on BEST [10]}

Ticket prices are a source of discontent and an often cited reason among motorists for not choosing public transport. Dissatisfaction with fare levels is also stated as a main reason behind Tallinn's zero fare policy that was introduced in January 2013. According to Cats et al., [11], 49 percent of the respondents in the annual citizen satisfaction survey stated that they were least satisfied with public transport fare levels. Next on the list came crowding (29\%) and service frequency (21\%). A proposal for a zero fare policy that applied to all Tallinn residents received a three-quarter majority vote in a popular referendum (ibid.). The adoption of the free-fare policy made Tallinn the first European capital to offer free public transport services to all its residents.

Fare levels affect passengers' economy directly and are as such a sensitive topic. Together with the low appreciation of public transport value for money and politicians' preferences for 'carrot' transport policy measures, it is no surprise that free, or low fare, policies are brought forward as a solution to many of the problems which our transport systems face. With few 
exceptions (e.g., the UK outside London), national or local authorities determine urban public transport fares. Traditionally, free public transport schemes are suggested to tackle three main objectives $[12 ; 13 ; 14 ; 15]$ :

- Environment: Motorists will park polluting cars and rather choose environmentally friendly transport

- Efficiency: Mode shift from car to public transport will reduce the need to build more and costly road capacity, make use of spare capacity in the public transport system, reduce road congestion, and correct for underpriced car use

- Distribution and Mobility: Free public transport benefits less well off groups of the population, like women, elderly, students and low-income households, and provide them with greater mobility.

During the last decade or so, environmental benefits are the most prominent reasons for proposing free public transport. However, traditionally, free public transport has perhaps even more frequently been proposed as a contribution to increase mobility, social justice and efficiency gains. For example, the early US free fare scheme proposals some forty years ago were often proposed on social and efficiency goals, like to improve mobility of students or to improve traffic circulation in central business districts. Today's campaigns and proposals tend to emphasis free public transport's potential to address environmental concerns.

This paper is motivated by the popular idea that low fares and free fares can have a number of beneficial effects and not least contribute to mode shift from the private car to public transport. The aim is to investigate the merits of free-fare and low fare policies with respect to benefits in terms of efficiency, modal shift, the environment and social issues. The paper presents evidence of the effects from a wide range of freefare schemes across mainly the western world.

The remainder of this paper is organised as follows. Section 2 gives a brief overview of relevant economic theory for public transport pricing. Section 3 presents evidence of free-fare schemes and their impact mainly from Europe but also the U.S., while section 4 provides conclusions and recommendations on the potential for free-fare schemes to meet their goals, and prerequisites for success.

\section{Pricing Theory}

Transport economics as a discipline has a long tradition of elaborating on the optimal levels of service and fares (early and notable contributions appeared frequently in Journal of Transport Economics and Policy and include [16, 17, 18; see also 19]. The welfare economics case for public transport subsidies include various sources of producer and user economies of scale; corrections for underpriced substitutes (car); and positive external benefits in terms of congestion relief and traffic safety gains. All these assumptions can, however, be challenged ${ }^{1}$. This section elaborates some central issues related to fare-setting of public transport services.

${ }^{1}$ A full account of this is outside the scope of this paper. Evidence to the contrary include, respectively: Econ [20] (Figure 6.6) finds that private cars in Norway pay more in taxes than their marginal external costs and that the opposite is true for buses, whose marginal external costs exceed taxes paid. Nash [21] analysed EU countries and found, similarly, that road revenues and taxes in most cases exceed infrastructure and external costs; there is conflicting evidence with respect to producer 
In economic theory, a necessary (Pareto) condition for optimal resource allocation is that prices equal (social) marginal costs per passenger or passenger kilometre. Three issues concerning marginal social cost pricing in urban public transport are of particular interest. One regards the problems relating to the peak periods. The other relates to the financing of urban public transport systems when there are scale economies, i.e., when average costs decrease as more passengers use the system. The third regards user economies of scale, or the Mohring effect. These three issues and their implications are described in some detail in the following subsections.

\subsection{The problem of the peak}

Marginal costs are relatively stable and low as long as passenger numbers are well below the public transport system's capacity. In the short run, however, there is limited room for increases in capacity to meet increased design capacity demand. Hence, short run marginal costs (SRMC) increase dramatically, or even infinitely. In addition, social SRMC increases as a result of passengers' disbenefit of crowding.

In the longer run, however, system capacity can be adjusted with new investments, and there is no sharp increase in marginal costs at a certain level of demand like in the short run case. Marginal costs are still higher during the rush periods than off-peak. The reason is, i.a. the fact that bus fleet and personnel cannot be utilised as efficiently to serve rush peaks as they can outside the peak periods. For example, within the period between 6am and 9am in the morning there can be a very sharp top, which lasts for maybe 30 minutes. Much of the bus fleet and personnel that are used to serve these passengers can only be used for one single roundtrip.

In sum, and regardless of whether our time horizon is long or short, peak passengers are associated with higher marginal costs than off-peak passengers. From an economic point of view peak fares should therefore cost more than off-peak fares. These costs should be allocated to a relatively small number of passengers, namely those who travel during the peak periods and on sections of the routes where capacity is at its limit (design capacity demand).

Off-peak marginal costs can, on the other hand, be very small and sometimes close to zero. There is usually plentiful capacity and little crowding. On this background TCRP [24] finds that off-peak free fares can be justified.

\subsection{Scale economies in production}

With scale economies, marginal cost falls as demand increases. This is due to high fixed costs and low additional costs of additional production of passengers or passenger kilometres. The marginal cost can sometimes be considered as being very low and sometimes near zero. Such a scenario implies that efficient pricing approaches a zero fare. However, there is little evidence suggesting that scale economies are generally present in local public transport. As suggested above, scale economies of production are more likely during off-peak periods.

economies of scale in local public transport - see also van Reeven [22] and Basso and Jara-Días [23] on user economies of scale; buses are themselves a major contributor to congestion and traffic safety gains can be offset by increased safety risk of walking to/from stops and stations. 


\subsection{The Mohring effect}

The Mohring effect (after Mohring [25]) is a first best efficiency case for subsidising public transport and relates to the fact that as more passengers use a public transport system, the system will expand in terms of more frequent services or more routes. This provides benefits to existing users, which are external to the new users. In this way there are user economies of scale, which from a welfare economics viewpoint should be reflected in lower fares. How much lower is an empirical question (se also footnote above), but user economies of scale are unlikely to justify free fares.

\subsection{Implications for zero fares policies}

An important feature of marginal cost pricing is the fact that passengers shall experience that each trip they make is associated with a cost. We have shown that the social marginal cost can be high (during peak) or low (off-peak and with user/producer economies of scale), but it will never be exactly zero.

However, passengers travelling at times of the day and at sections of the routes where there is ample capacity probably incur a cost that is closer to zero than to the cost of a typical single ticket. Season ticket can be a practical pricing tool for this kind of trips, provided they can be limited in time (off-peak only) or in geography (low-demand sections and low-demand travel directions in the network).

If scale economies are in fact apparent and if it is decided that efficient (i.e. marginal social cost) pricing shall be the norm, then authorities should also accept very low (off-peak) fares and be willing to allocate sufficient funds to cover the operator's deficits. It also implies that price differentiation must be accepted, e.g. between high peak fares and low, or free, off-peak fares.

\section{Evidence of Free-fare Schemes and their Effects}

Most free public transport schemes are relatively straightforward. Anyone who meets the requirements can travel without paying. In many cases the travellers must carry an ID card or documentation that they qualify for free travel, like for example proof of age, proof of residence or student ID. There are cases where low threshold barriers are in place, which in part contribute to reduce excess use or "unnecessary" travels. An example of this is the reimbursement scheme for season tickets for students at Flemish-speaking universities in Brussels, where students first had to purchase the season pass and then apply for a refund [26].

Where free public transport is introduced, it is often limited in one way or another. Usually, it is not offered universally. It can be geographically limited to a city, or to its central business district. Another type of limitation relates to passenger characteristics, like age, residency, disability, income, or whether they are registered students. A combination of such criteria is also relatively common. Yet another type of free public transport is related to specific services, like for example park and ride $^{2}$.

\footnotetext{
${ }^{2}$ In principle, season ticket travels can also be treated as "free" in the sense that once they are purchased there is no extra money cost of an extra trip. On the margin a passenger with a season pass will behave as if public transport were free.
} 


\subsection{Examples of free-fare schemes}

Besides the recently launched free public transport scheme in Tallinn, Estonia, the most oft-cited free-fare schemes in Europe are those of Hasselt in Belgium and Templin in Germany. Many more cities, towns and rural areas across the world provide free or very low priced public transport. Lists and facts are easily available on the internet [27]. This section presents some schemes which are well known and/or reasonably well documented or evaluated.

From January 2013, public transport has been free for residents of Tallinn [28], the capital of Estonia with about 425,000 inhabitants. There have been high expectations with respect to the scheme's achievements in terms of travel behaviour change and local finances. The latter relates to the fact that farebox revenues covered only around 30 percent (or app. EUR 12m) of operating costs prior to the introduction of the scheme and that even a relatively modest increase in registrations of residency will generate sufficient tax revenues to offset the lost ticket revenues [29].

The Belgian city of Hasselt is probably the most often encountered success story of free public transport. Free public transport was introduced in 1997 along with a number of other measures to reduce the problems and investment needs caused by the large and growing road traffic. Hasselt is a city of about 70,000 inhabitants. Before the free-fare was introduced the public transport system was very modest. The two main routes operated hourly services [30]. After more than a decade of free fares and more than tenfold increase in passenger numbers, public transport patronage in Hasselt amounts to about 65 trips per capita per year - up from about 5 trips per capita in 1997. In spring 2013, the freefare scheme was decided to be abolished due to rising costs [31].

The German town of Templin introduced free public transport for all in 1997. A specific goal was to reduce external costs of private transport. The town, which at that time had about 14,000 inhabitants and 2-4 bus lines, experienced a 12-fold increase in passenger numbers within few years - from about 3 trips per capita per year to about 37 (calculated from figures in [13]).

Since 2009, public transport has been free for all users in Aubagne, France, and surrounding municipalities. The total population of the participating municipalities is about 100,000 . Free public transport was introduced for social reasons and due to the fact that ticket revenues covered less than 10 percent of the public transport system budget [11]. In other words, the public already financed almost all operating costs even before the scheme started.

Both in England and Scotland, local authorities are required to provide free transport for residents over 60 years and for persons with disabilities. The requirement applies to off-peak periods, and the competent authority compensates bus operators on the principle of "No better, no worse off", financially. Main objectives of the scheme are to create a more inclusive society and to provide disadvantaged population groups with improved mobility and welfare. When the scheme was first introduced nationally, local authorities could charge a maximum fee of $£ 5$ for issuing old age pensioner-id-cards [32], which partly worked as a low threshold barrier to adoption.

In Norway the city of Stavanger established a free city centre bus service for a short period between August and December 2011, as a trial of limited duration. The scheme offered a new, frequent, free and environmentally friendly circular bus service. In 2003, a major parking facility in the city of Bergen started to run a free shuttle bus to the city centre, with departures every 10 minutes and available to everyone. The shuttle was abandoned in 2011 for financial reasons. 
TCRP [24] and Hodge [12] show that there are many places in America with free public transport. Many of these were established in the 1970s and 1980s. A dominant motivation was to increase mobility, especially for students and in city centres, and also as a means to promote public transport.

\subsection{Impacts and effects}

Detailed and elaborate ex-post evaluations of free fare schemes are scarce in the published literature. This does not necessarily mean that evaluations aren't undertaken, but it means that most of the available evidence, with some honourable exceptions, is in the form of opinions based on general knowledge of demand and supply, attitudes and behaviour. Further, there is abundant anecdotal evidence of effects and achievements, which fall into the subjective opinion of the authors and their organisations. The following sections attempts to critically examine and present some of the key impacts and effects as reported by various sources.

3.2.1. Passenger growth, mode shift and environmental benefits: The main effect of free public transport is to significantly increase patronage. Strong passenger growth is reported from everywhere where free public transport is introduced. This is probably the main reason why earlier U.S. evaluations report their schemes as successful. A main objective of those schemes was indeed to increase mobility and patronage.

Passenger growth usually exceeds expectations, and the effect builds up over a prolonged period of time. For example, passenger growth was still substantial some ten years after free fares were introduced [33]. However, the size of the growth varies considerably from place to place, and free fare is often a part of a larger package of public transport improvements or car restrictions. Different cities and towns report traffic growth of everything from a modest 2030 percent (e.g., Mercer, New Jersey [11], up to 10- and 13-fold increase (Hasselt [11] and Templin [13], respectively; various sources cite different levels of growth). The free fare is often a part of a package of measures, which include service improvements and/or restrictions on car. Therefore, evaluations are often unclear about the isolated effects of the free-fare. There is no doubt, however, that free public transport contributes substantially to increased mobility for those who are entitled to free travel.

Still, with currently about 65 public transport trips per capita per year, Hasselt places itself below or in line with many European midsized cities and towns. As comparison, using 2011 public transport data from Statistics Norway, the number of local bus trips per capita in similarly sized Norwegian cities are 112 in Tromsø (70,000 inhabitants), 103 in Trondheim (180,000 inhabitants), 68 in Kristiansand (84,000 inhabitants) and 62 in Ålesund (45,000 inhabitants). All these cities charge regular fares.

In addition to trip generation there is also considerable mode substitution. The low cross price elasticity of car use with respect to public transport fares means, however and according to Storchmann [13], that free public transport is unsuitable instrument for reducing car use and its external costs. Motorists' behaviour and mode choice depend very little on public transport fares.

The city of Stavanger [34] evaluated its free bus scheme. The intended effects were that it would help reduce greenhouse gas emissions, increase mobility and access and reduce car dependency. The evaluation finds no data to support the hypothesis that the service replaced downtown car use and hence greenhouse gas emissions. Nearly half the passengers would otherwise walk, and a further 11 percent took the bus only for fun. The evaluation shows, however, that the free bus service offered increased access and mobility. The service became 
a popular place to spend time. In this way it not only experienced considerable demand with 7-8 passengers per departure, it also served as a meeting point especially for young people.

The free bus in Bergen supplied about 160 bus departures per day into the city centre. Lynnum [35] estimated that the service reduced the number of car trips into the city centre by about 160 per day. In total, this means that 160 cars were replaced by 160 buses in a relatively narrow city centre. Additionally, the same evaluation estimates that the free bus generated some 90 daily car trips outside the city centre. The service was popular and improved access, but did not reduce traffic problems in Bergen.

With respect to mode shift, the general picture observed in most cities is that the source of the increased passenger numbers is overwhelmingly people who alternatively would have walked, cycled or not travelled at all. There is also a large group that alternatively would have used other public transport services. Very few come from car. Quoting earlier studies Storchmann [13] documents that cross price elasticities of demand for car use with respect to public transport fares are virtually zero. That is, transit fares hardly have any short run impact on car use. In the longer run, Dargay and Hanley [36], cited in Litman [37], find that public transport fares have larger effect. They find long run cross price elasticity of demand for car use w.r.t. fares of around 0.3. TCRP [24] shows that free public transport in U.S. city centres mainly has attracted passengers who would otherwise walk. The Danish Board of Technology [38] estimates that 10-20 percent of traffic growth following an introduction of free public transport in Denmark will be diverted from previous car drivers. In larger cities they expect a larger share. In Hasselt, the Danish Board of Technology [38] reports that about one-eighth of the passengers in Hasselt were former car drivers and that half the new passengers were induced, i.e., they would otherwise not have travelled. van Goeverden et al., [30] report slightly different figures from Hasselt, namely that "new users", i.e., passengers who did not travel by public transport before, constitute 37 percent of passengers - of which 16 percent are diverted from car, 12 percent from bicycle and 9 percent from walking. The brunt of the passenger growth is in other words former public transport users making more bus trips. Cervero [39] found that free buses have negligible effect on car traffic volumes in American cities. Storchmann [13] reports that in Templin, most of the new public transport journeys replaced non-motorised transport, of which 30-40 percent would be cycling trips and 35-50 walk trips. And just like the Danish estimate, about 10-20 percent of the new Templin bus demand replaced car trips. One account of substantial shift from car to public transport is provided in Cats et al., [11]. Without any references, they report that the Aubagne scheme doubled passenger numbers, of which 20 percent were induced trips. Of the remaining, 63 percent were former motorists and 27 would have walked.

3.2.2. Service performance: There are several accounts that service reliability and punctuality suffer when public transport is made free. Passenger numbers are less predictable and it is difficult to keep time schedules when time spent at stops varies. More passengers on board means longer boarding and alighting times (see, e.g., Cervero [39]) and also that the bus must make more stops (see, e.g., Hodge [12]; Storchmann [13]). It also increases crowding disbenefits for other passengers.

With free fares, increased demand is not associated with a similar increase in revenues. Therefore, it is reasonable to expect that crowding on board will increase. Many reviews discuss this problem, which is the reason why Hodge et al. [12] do not recommend free public transport for all in major cities, and the reason why TCRP [24] recommends limiting free scheme to off-peak periods. 
Usually, service levels are increased in order to meet the new demand. More routes and more departures are a benefit to all passengers and makes public transport more attractive and user friendly - the Mohring effect.

3.2.3. Peak spreading: Free fares prior to or after peak periods will encourage passengers who can choose their departure time to make the trip when it is free. In this way the public transport system can reduce the burden and requirements of the peak by spreading it. Free public transport for elderly in the UK is an example of this. It is mandatory after 9:30am according to the Concessionary Bus Travel Act of 2007.

Storchmann [13] refers to different studies and demonstrate that passengers are not very sensitive to price signals when it comes to trip timing. Substitution between peak and offpeak is very unlikely and price differentiation has little potential to change passengers' time of travel. Cervero [39] also concludes that free fares have virtually no effect with respect to peak spreading. Currie [40] analyzed the impact on crowding relief of free trains before the morning peak in Melbourne, Australia. Between 1.2 and 1.5 percent of the peak hour passengers adjusted and travelled earlier. Unfortunately, the general passenger growth is greater than this, and the measure has therefore only given a marginal ease. Still, Currie considers the scheme worthwhile because it frees up very expensive additional peak capacity.

3.2.4. Distribution and social cohesion: The Danish Board of Technology [38] finds that free public transport in Denmark will have positive distributional effects. Low-income groups will benefit most. Rye and Mykura [14] point out, however, that free public transport for elderly and disabled as a universal instrument for social inclusion in Scotland is no accurate measure. They find that new users are mainly younger elderly, car owners, more well off, and so on, although a large proportion in the lowest income groups reported improved quality of life. Therefore, they conclude that the mandatory bus concession for older and disabled people ties up funds which could have been used more effectively and efficiently with other policy measures.

TCRP [24] and Hodge et al. [12] describe several US examples of free public transport that were introduced in the 1970s and 1980s. Many of these schemes were aimed at improving mobility, especially for students and in city centres. Given these goals, many schemes are judged "successful". Free public transport contributed to increase mobility (demand) among the targeted groups.

3.2.5. Costs and cost effectiveness: Although free public transport is straightforward from the passengers' point of view, it is difficult to estimate revenue shortfalls and increased operating costs associated with patronage growth. The example from England, where commercial bus operators are entitled to be reimbursed for their losses due to the free fare for elderly and disabled, is illustrative. The UK Department for Transport [41] is a 100+ pages guidance document on the calculation of reimbursements of bus operators for mandatory free travel. The guidance is regularly updated with new specifications, narrower definitions, etc., which suggests the importance and potential for disputes over a large number of assumptions and parameters. The guidance is accompanied by a spreadsheet reimbursement calculator which clearly illustrates the complexity of calculating revenues foregone and costs incurred.

The cost of introducing free public transport is not limited to the ticket revenues forgone. Except in situations with very low traffic base and ample spare capacity, increased demand will have to be catered for with increased service levels, i.e. more buses and more drivers. In Hasselt, for example, van Goeverden et al., [30] report that the number of busses increased by a factor of five from 8 to 40 and that the number of bus lines increased from four to nine. 
Service frequencies were also improved. This extra capacity is especially costly during rush hours in larger cities, due to the higher nominal volumes in cities and because congestion is usually more severe. Therefore, there are many examples of zero tariff which only applies outside the morning rush hour, and more rarely - with notable exceptions like Tallinn and, for certain population groups, London - free travel throughout the day.

To be deducted from these costs are expenses related to ticketing, ticket inspections, cost of money handling and safety measures to prevent robbery.

The cost of operating a free service varies with the size of the scheme and on subsidy rates prior to the introduction of the scheme. According to Cats et al., [11] ticket revenues in Aubagne covered only 9 percent of the system costs and an abolition of fares would necessarily not add much to current subsidies. Osloby [42] refers cost estimation for free public transport in Oslo. Estimated costs are NOK 2.9 billion in lost ticket revenues and another NOK 2.5 billion in increased operating costs - a total of NOK 5.4 billion (about $€ 0.7$ bn). Lynnum [35] reports that costs of running the free shuttle bus in Bergen, where three buses were in operation, was NOK 3.2 million per year annually (just under $€ 0.5 \mathrm{~m}$ ), and was covered by the parking company. When the service was discontinued in 2011 the local newspaper reported an annual cost of about NOK $10 \mathrm{~m}(€ 1.3 \mathrm{~m})$. The free bus service in Stavanger cost NOK 1.3 million during the four months it was in operation $(€ 0.17 \mathrm{~m})$.

Storchmann [13] considered costs of free public transport in Templin. The scheme gave some savings in ticketing and ticket inspection costs. It is unclear whether the scheme gave any efficiency gain in terms of faster passenger boarding because of the large passenger growth, which probably had an offsetting effect. The cost of providing more peak capacity to cater for the greatly increased demand was estimated to be 2-4 times the cost savings in operation and maintenance of the ticketing system (Storchmann [13].

Tallinn's economic case for introducing free public transport is very different from any other free-fare scheme. One stated objective is to "increase the municipal income tax by providing a stimulus to register as a resident of Tallinn" (Cats et al., [11] p3). New registrations of residency will generate tax revenues and the net effect on Tallinn's finances may in fact be positive. According to City of Tallinn [28] there was a significant increase in registered residents already during the first month of the scheme's operation. These were probably Tallinn residents registered in other regions, who had not previously had the incentive to submit notice of removal.

Hodge et al., [12] hold that free public transport will always improve cost effectiveness when measured as operating costs per passenger. The reasoning is that load factors increase. On the other hand, it is likely that a fully 100 percent subsidised service will lose its focus on cost effectiveness and market orientation. In line with this, Gannon and Liu [43] argued that subsidies may weaken operators' incentive for cost control and expose opportunities for rentseeking behaviour. Indeed, Bly and Oldfield [44] found that on average for 16 different countries a $1 \%$ increase in subsidy will diffuse into only $0.31 \%$ fare reductions, $0.05 \%$ increase in services, but $0.62 \%$ leakages in terms of higher unit costs and reduced productivity.

3.2.6. Other effects: Storchmann [13] shows that the free public transport scheme in Templin had positive side effects that were not considered ex-ante. While the effects on infrastructure, city image and production costs add up to more or less zero - nothing - he observes a substantial traffic safety gain. This is based on the theoretical argument that accident rates are substantially higher for walking and cycling than for public transport. Mode shift from walk/cycle to public transport is therefore associated with a reduced number of accidents. This finding is applicable to most schemes and circumstances. Comparing international 
accident statistics, Elvik et al., [45, figure 3.10] present relative accident rates for different modes, including walk, cycling, car and bus. While bus passengers' accident risk is only half the risk of car drivers and hence relatively safe, pedestrians and bicyclists face accident risks that are between 6.7 and 9.4 times higher than for car. However, neither Elvik nor Storchmann mention any potential negative public health effects when people stop walking and cycling.

Health effects are indeed discussed by Jones et al., [46]. They regard health and wellbeing in the broadest sense when they study free buses in London for children up to 18 years (provided they are in education). The authors argue that free public transport has positive effects for children and youth in that the bus is a place for interaction, socialisation and increased independence. Although the use of buses replaces many shorter walk trips, there are also benefits in that it generates walking to and from bus stops, and that young people are active on board (sic).

Also the Stavanger free bus evaluation [34] shows that free bus served as a popular meeting place and residence for young people, even between school lectures. A similar phenomenon is reported from Mercer, New Jersey. A disproportionally high share of new passengers was youths [11].

Contrary to Jones et al.'s [46] positive view of young people's activities on board, there is a relatively large amount of evaluations which report vandalism, insecurity and confrontation as a result of free fare schemes. Cervero [39], the Danish Board of Technology [38] and Hodge et al., [12] are among those who mention this problem. Danish Board of Technology [38] points out that free fares give public transport lower status and that buses can be refuges for "socially deprived people without actually transport needs" (p 84). While the EU Green paper on urban mobility [5] (p. 16) underlines the importance of personal security for choosing public transport, free public transport is likely to worsen the problem and deter people from using public transport.

\section{Conclusions and discussion}

Fare levels affect many people's finances directly. Like any other product, the price also shapes expectations and attitudes. There is a general attitude that public transport should be "cheap", both of social, environmental and efficiency reasons.

While proposals to introduce free public transport are generally optimistic with respect to its potential to deliver environmental benefits, congestion relief, social distribution, and so on, there is great scepticism in the scientific literature that free public transport is suitable for achieving any goals other than massive patronage growth. For all other goals and purposes free public transport offers no, or low, goal achievement at very high costs $[38 ; 39 ; 13]$. Transport and social policy goals can be met more effective and at a lower cost with more specific measures. van Goeverden et al., [30] is a possible exception. They see a potential role for targeted use of free public transport for specific groups like off-peak free travel for students and the elderly. Neither can it generally be said to be true that local public transport systems exhibit sufficient levels of off-peak free capacity or scale economies to justify free fares.

The principle of specificity is an insight shared by all social sciences. As far as possible, policy measures must target a problem or a policy objective directly. Goal achievement is greatest when a policy measure directly addresses the defined problem. This means, for example, that reductions in car traffic are best obtained through restrictions on car use. It follows that public transport fares are well suited to influence public transport passenger demand volumes, and less effective in changing anything else. There is a clear limit as to what public transport fares-and service quality-can do to change car use or the environment. 
However, it appears that mode change can be obtained between public transport on the one side and walk and cycle on the other.

Free public transport can greatly improve public transport modal share, not by taking passengers from other motorised modes, but through the generation of substantial amounts of new travel and by substituting walk and cycle trips.

So, when can zero fares policies be justified? The Danish Board of Technology [38] assessed the implementation of free public transport in different areas in Denmark. They conclude that the free public transport is best suited in larger cities where the potential for mode shift from car is greatest. Cervero [39] also finds that experiences with free fares are better in central city areas, although the effects are in general small. In contrast to this, Hodge et al., [12] find that the free fares create crowding problems in larger cities, and less so in smaller towns. Therefore, they see a greater potential for free public transport to succeed outside of the big cities. TCRP [24] argues that free public transport is a relatively good measure during off-peak periods. Off-peak passenger growth can be handled by spare capacity in the public transport system. Free public transport appears, however, to be rational and effective in two particular cases:

- The first is promotions of limited duration. A new route or a new service can gain momentum if it is launched in tandem with free travel-for a limited time. A zero fare campaign can, likewise, make the population aware of existing public transport (see, e.g., Strand [47]). The Danish Svendborg Railway introduced free fare a month in 2004 as an apology following a period of numerous service interruptions [38].

- The second case is when the cost of operating a ticketing system and related activities exceed ticket revenues. Free public transport may be a pragmatic solution when the ticket income is very low. Several examples that ticketing is removed altogether, both in Sweden and in Denmark, are the result of such a situation.

Can free public transport still be a part of an effective and efficient package of measures? The general answer to this is most likely 'no'. However, the situation can be greatly improved if an existing free-fare scheme is supplemented with more specific measures. The Danish Board of Technology [38] mentions that goals for car reduction can only be met with policy packages that include "stick" measures in addition to 'carrots'. This means, for example, that reduced car use and mode shift towards public transport can be obtained more effectively if zero fare schemes are accompanied with restrictions on car use and car parking. The example of Bergen calls for another type of policy package. The evaluation showed that free public transport had negative impact on the local environment - 160 passenger cars per day were replaced by 160 buses per day. This negative side effect could in part have been remedied by the use of more environmentally friendly buses, like in Stavanger, or through full electrification of the bus fleet. In cases where the goal is to improve the situation of mobility impaired people, like in the UK, free buses only tackle one part of their problem. Clearly, focus must also be on accessibility of bus stops and stations, which may be a necessary condition for their bus use, and on other factors affecting their need, willingness and ability to travel. Free buses can only contribute to improve mobility for disabled people if the entire package of such measures is in place.

Proponents of free fare schemes undoubtedly always will be found and they are sometimes quite visible in the public - not least in social media. The idea is captivating to many and indeed to those who will benefit from it. Free public transport gained broad public support in Tallinn and is likely to enjoy similar popular support most places. Free public transport as a political goal in its own right is of course legitimate. But when free fare schemes are 
advocated and justified as a means to meet environmental, social or efficiency goals, the evidence presented here suggests that the arguments are largely misguided.

A further challenge with free public transport is related to market orientation. The price paid is a good indicator of passengers' needs and preferences and an incentive for the operator to win new passengers and keep the existing ones. With no ticket revenues it is easy to imagine that services lose their customer orientation. The problem must be solved by way of market and performance monitoring, customer surveys, management by objectives and others.

Free public transport is a costly policy. The costs will further rise as patronage levels soar. This means that free public transport necessarily must displace funds from other policy areas or increase public budgets in one or another way. There is some evidence that free-fare schemes have been abandoned because of their high and rising costs. While the current global economic downturn puts more stain on public budgets which again may prompt authorities to abandon freefare schemes, there is a rising amount of evidence that fare increases have larger effect than similar fare reductions. See, e.g., Lin et al., [48] or Dargay and Hanley [12]. This means that the total outcome of introducing free fares and later withdraw the scheme can be negative. This means that successful free fare schemes require broad political support and long term commitment.

\section{References}

[1] EU, "Roadmap to a Single European Transport Area - Towards a competitive and resource efficient transport system", White paper 2011, COM, (2011).

[2] Norwegian Ministry of the Environment, "Norwegian climate policy", White paper, (2011-2012).

[3] EU, "Action Plan on Urban Mobility", Communication from the Commission to the European Parliament, the Council, the European Economic and Social Committee and the Committee of the Regions, (2009), $\mathrm{COM} / 2009 / 0490$ final.

[4] UITP, "UITP Istanbul bus declaration", http://uitp.org/advocacy/pdf/declarations/declaration_a2manifesto2.pdf.

[5] EU, Green paper, "Towards a new culture for urban mobility", COM (2007).

[6] A. Nossum and N. Fearnley, "Decision-makers' preferences for different policy instruments under various conditions", Paper presented at the 2nd International Conference on Funding Transportation Infrastructure, (2007) September.

[7] B. S. Frey, "Why are Efficient Transport Policy Instruments So Seldom Used?", In: J.Schade and B.Schade (eds.): Acceptability and Transport Pricing Strategies, (2003), pp. 203-218, Amsterdam: Elsevier Ltd.

[8] R. Balcombe, R. Macett, N. Paully, J. Preston, J. Shires, H. Titheridge, M. Wardman and P. White, "The demand for public transport - a practical guide", TRL Report 593, (2004).

[9] N. Fearnley and J. -T. Bekken, "Long-term demand effects in public transport", Paper presented to the European Transport Conference in Strasbourg, France, AET/PTRC, (2005).

[10] BEST 2011, "BEST report 2011: Results of the 2011 survey”, BEST Benchmarking in European Service of public Transport, Helsinki, (2011) May.

[11] O. Cats, Y. Susilo and J. Eliasson, "Impacts of Free PT, Tallinn - Evaluation Framework", (2012) October, KTH Royal Institute of Technology, http://www.tallinn.ee/eng/tasutauhistransport/g9616s62872.

[12] D. C. Hodge, J. d. Orrell and T. R. Strauss, "Fare-free policy: costs, impacts on transit service, and attainment of transit system goals", Washington State Transportation Centre, (1994).

[13] K. Storchmann, "Externalities by Automobiles and Fare-Free Transit in Germany - A Paradigm Shift?", Journal of Public Transportation, vol. 6, no. 4, (2003), pp. 89-105.

[14] T. Rye and W. Mykura, "Concessionary bus fare for older people in Scotland - are they achieving their objectives?”, Journal of Transport Geography, vol. 17, (2009), pp. 451-456.

[15] H. J. Baum, "Free public transport", Journal of Transport Economics and Policy, vol. 7, no. 1, (1973), pp. 319.

[16] P. K. Else, “Optimal pricing and subsidy for scheduled transport services”, Journal of transport economics and policy, vol. 19, no. 3, (1985), pp. 263-279. 
[17] J. O. Jansson, "Marginal cost pricing of scheduled transport services: a development and generalisation of Turvey and Mohring's theory of optimal bus fares", Journal of Transport Economics and Policy, vol. 13, no. 3, (1979), pp. 268-294.

[18] K. Jansson, "Optimal public transport price and service frequency", Journal of Transport Economics and Policy, vol. 27, no. 1, (1993) January, pp. 33-50.

[19] S. Glaister, (Ed.), “Transport subsidy”, Newsbury, Policy journals, (1987).

[20] Econ, "Eksterne marginale kostnader ved transport [Marginal external costs of transport]", Rapport 2003-054, (2003), http://www.econ.no/stream_file.asp?iEntityId=1831.

[21] N. Nash, P. Bickel, R. Friedrich, H. Link and L. Stewart, "The environmental impact of transport subsidies", OECD workshop on environmentally harmful subsidies, Paris, (2002) November 7-8, http://www.oecd.org/site/agrehs/35215697.pdf.

[22] P. van Reeven, "Subsidisation of Urban Public Transport and the Mohring Effect", Journal of Transport Economics and Policy, vol. 42, no. 2, (2008), pp. 349-59.

[23] L. J. Basso and S. R. Jara-Díaz, "The Case for Subsidisation of Urban Public Transport and the Mohring Effect”, Journal of Transport Economics and Policy, vol. 44, no. 3, (2010), pp. 365-372.

[24] TCRP, "Transit Pricing and Fares", Traveler response to transportation system changes, Transportation Research Board, Report 95 Chapter 1, (2004).

[25] H. Mohring, "Optimization and scale economics in urban bus transportation", American Economic Review, vol. 62, (1972), pp. 591-604.

[26] A. De Witte, C. Macharis, P. Lannoy, C. Polain, T. Steenberghen and S. Van de Walle, "The impact of"free" public transport: The case of Brussels", Transportation Research Part A, vol. 40, no. 2006, (2006), pp. 671689.

[27] Free public transport, http://en.wikipedia.org/wiki/Free_public_transport.

[28] City of Tallinn, "Free public transport in Tallinn", Tallinn news 14.01.2013, (2013), http://www.tallinn.ee/eng/tasutauhistransport/Free-public-transport-inTallinn?\&filter_otsing_uudis_rubriik_id=160.

[29] Euro Cities, "Residents enjoy free public transport in Tallinn", Article 18 Feb 2013, (2013), http://www.eurocities.eu/eurocities/news/Residents-enjoy-free-public-transport-in-Tallinn-WSPO-952EDX.

[30] C. van Goeverden, P. Rietveld, J. Koelemeijer and P. Peeters, "Subsidies in public transport", European Transport $\backslash$ Trasporti Europei, vol. 32, (2006), pp. 5-25.

[31] Eltis, "Hasselt cancels free public transport after 16 years", Eltis news posted 17.04.2013, (2013), http://www.eltis.org/index.php?ID1=5\&id=60\&news_id=4183.

[32] DETR, “A new deal for transport: better for everyone - white paper", White paper, UK Department for Environment, Transport and the Regions, (1998).

[33] City of Hasselt, "10 jaar bussen”, (2013), http://www.hasselt.be/nl/content/2436/10-jaar-bussen.html.

[34] Stavanger, "Nullen og nye gågater [The 'Zero' and new pedestrian streets]", Stavanger municipality, (2012).

[35] F. Lynnum, "Gratsbuss i Bergen. En evaluering av gratis parkeringsbusstilbud i Bergen sentrum [Free bus in Bergen. An evaluation of free parking shuttle in Bergen centre]", Asplan Viak, UTB 2004/11, (2004).

[36] J. Dargay and M. Hanly, "Bus fare elasticities" ESRC Transport Studies, Unit, University College London, Cited in Litman, (2004).

[37] Litman, "Transit Price Elasticities and Cross-Elasticities", Journal of Public Transportation, vol. 7, vo. 2, (2004), pp. 37-58.

[38] Danish Board of Technology, "Perspektiver ved indførelse af gratis offentlig transport - vurderinger og anbefalinger fra en arbejdsgruppe under Teknologirådet. [Perspectives of free public transport - Assessments and recommendations from a working group in the Danish Board for Technology Assessment]", Teknologirådets rapporter 2006/16, (2006).

[39] R. Cervero, "Transit Pricing Research. A Review and Synthesis", Transportation, vol. 17, (1990), pp. 117139.

[40] G. Currie, "A Quick and Effective Solution to Rail overcrowding - the Melbourne Free "Early Bird" Ticket Experience", Paper submitted for publication and presentation, Transportation Research Record, (2010).

[41] UK DOT, "Concessionary travel for older and disabled people: guidance on reimbursing bus operators", (2012) November, Department for Transport.

[42] Osloby, "Her kjører du gratis trikk og buss [Here you can travel for free with bus and tram]", (2012) September 6.

[43] C. A. Gannon and Z. Liu, "Poverty and Transport World Bank", Discussion Paper No. TWU-30, (1997).

[44] P. H. Bly and R. H. Oldfield, "Relationships between Public Transport Subsidies and Fares, Service Costs and Productivity", TRRL Research Report 24 / Dept. of Transport, (1985).

[45] R. Elvik, A. Høye, T. Vaa and M. Sørensen, "The handbook of road safety measures", Second edition, Bingley, UK: Emerald, (2009). 
[46] A. Jones, R. Steinbach, H. Roberts, A. Goodman and J. Green, "Rethinking passive transport: Bus fare exemptions and young people's wellbeing”, Health \& Place, vol. 18, (2012), pp. 605-612.

[47] A. Strand, "Evaluation of the campaign I drive green in Troms $\varnothing "$ ", TOI report 966/2008, Oslo: Institute of Transport Economics, (2008).

[48] J. -H. Lin, T. -R. Lee and W. Jen, "Assessing asymmetric response effect of behavioral intention to service quality in an integrated psychological decision-making process model of intercity bus passengers: a case of Taiwan", Journal Transportation, vol. 35, no. 1, (2007).

\section{Author}

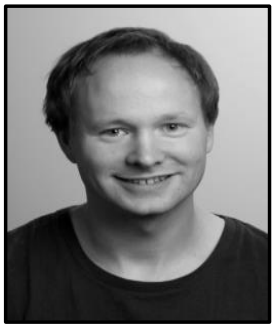

\section{Nils Fearnley}

Nils Fearnley is a transport economist and senior researcher in urban and passenger transport at the Norwegian Institute of Transport Economics (TØI). His research interests include the financing of public transport; financial, economic and social aspects of transport; market analyses; and transport policy. 
International Journal of Transportation Vol.1, No.1 (2013) 